Disabil Rehabil Assist Technol. Posted online on October 1, 2013.

(doi:10.3109/17483107.2013.840861)

\title{
Which activities threaten independent living of elderly when becoming problematic; Inspiration for meaningful service robot functionality.
}

Bedaf S, Gelderblom GJ, Syrdal DG, Lehmann H, Michel H, Hewson D, Amirabdollahian F, Dautenhahn K, de Witte L.

\begin{abstract}
Purpose: In light of the increasing elderly population and the growing demand for home care, the potential of robot support is given increasing attention. In this paper an inventory of activities was made that threaten independent living of elderly when becoming problematic. Results will guide the further development of an existing service robot, the Care-O-bot®.

Method: A systematic literature search of PUBMED was performed, focused on the risk factors for institutionalization. Additionally, focus group sessions were conducted in the Netherlands, United Kingdom, and France. In these focus group sessions problematic activities threatening the independence of elderly people were discussed. Three separate target groups were included in the focus group sessions: 1) elderly persons $(n=41), 2)$ formal caregivers $(n=40)$, and 3$)$ informal caregivers $(n=32)$.

Results: Activities within the ICF domains mobility, self-care, and interpersonal interaction \& relationships were found to be the most problematic.

Conclusions: A distinct set of daily activities was identified that may threaten independent living, but no single activity could be selected as the main activity causing a loss of independence as it is often a combination of problematic activities which is person-specific. Supporting the problematic activities need not involve a robotic solution.
\end{abstract}

\section{Introduction}

In western societies sustaining independent living of elderly is preferred by most citizens and a target for societal policies. Nonetheless, when people age, they are faced with the negative consequences of their decreasing abilities which, among other factors, can threaten their independent living. Age-related changes to mental and physical abilities can make the performance of everyday tasks difficult or challenging. For those who are not able to maintain their independence, societies seek different kinds of solutions towards regaining or sustaining independence, or alternatively offer an institutional arrangement for dependent living. Risk profiles for institutionalization are very useful for developing interventions to prevent the need for nursing home admission and designing non-institutional alternatives to costly long-term institutional care. However, the causes of the institutionalization of an elderly person are certainly complex ${ }^{1}$. Regardless of the housing situation, care is traditionally provided either informally by those from the direct social environment (e.g. family) or more formally by professionals funded by either public or private means. However, social structures have changed, which have resulted in family members being less inclined and/or able to provide care. Due to this change and the increasing shortage of care $\operatorname{staff}^{2}$ alternative solutions are being given increasing attention, with technology as the alternative with the highest potential. Of course, technology is already being used to support independence. Assistive technology (AT), such as wheelchairs, stair lifts, patient hoists, smart home technologies, and in general accessibility adaptations of the home, has come a long way in supporting individuals in their independence ${ }^{3}$. But with the ongoing development of technology new possibilities emerge for supporting independent living. A new emerging field in AT is robotics. Robotics has the potential to support care and independence in many ways ${ }^{4}$. Although there is still only limited application of robotics in care, substantial effort is being taken to develop applications. The envisioned role of the robots in these developments, and the type of tasks the robots perform, are primarily guided by technical feasibility and to a lesser degree by the target users' needs ${ }^{5}$. Over the past decades several projects have developed a range of functionalities. Nevertheless, only a small number of robot systems have actually been brought to the market and made available to support care for individuals in their daily lives. This raises questions concerning the suitability of the robots to actually answer the needs of users.

In the ACCOMPANY project (Acceptable robotiCs COMPanions for AgeiNg Years) an existing service robot's functionality will be further developed to support older citizens to sustain independent living ${ }^{6}$. This robot should be able to assist elderly persons in being able to carry out problematic daily tasks on his/her own. The type of robot pursued in the ACCOMPANY project, the Care-O-bot ${ }^{\circledR}$ (Fraunhofer IPA, Stuttgart, Germany), aims to support activities and is not aimed at replacing lost or declined human abilities as such. The focus of this study is therefore on the activities older people perform and not on their abilities. Humans perform a very wide range of activities, any of which could potentially become difficult for older people to perform, thereby threatening 
independent living. The first goal of the ACCOMPANY project is to understand the needs of future users, regardless of perspectives related to availability of technological solutions.

This paper presents the results of a systematic literature search in PUBMED and the results obtained during focus group sessions conducted with elderly persons, formal caregivers, and informal caregivers in the Netherlands, the United Kingdom, and France, surveying the problematic daily activities which result in elderly persons dependency. This survey process was guided by the following question: Which problematic activities in daily life are most threatening the independence of elderly persons? The idea is that the answer to this question might subsequent be leading for the development of robot functionalities.

\section{Method}

First a systematic literature search was conducted followed by focus group sessions. To deal with the variety of pertinent activities, the International Classification of Functioning (ICF) of the World Health Organization (WHO) was adopted to group activities human perform. The ICF provides a structured taxonomy for the description of human functioning ${ }^{7}$. Within the ICF the subgroups of section d, Activities and Participation, were especially considered to be relevant as the focus here is on the activities people perform and not on their ability which is also the focus of this paper.

\subsection{Literature}

The data collection process to find articles, concerning risk factors (related to daily activities) for the institutionalization of elderly persons, consisted of two tracks: a systematic search in Pubmed and a hand search (see Figure 1).

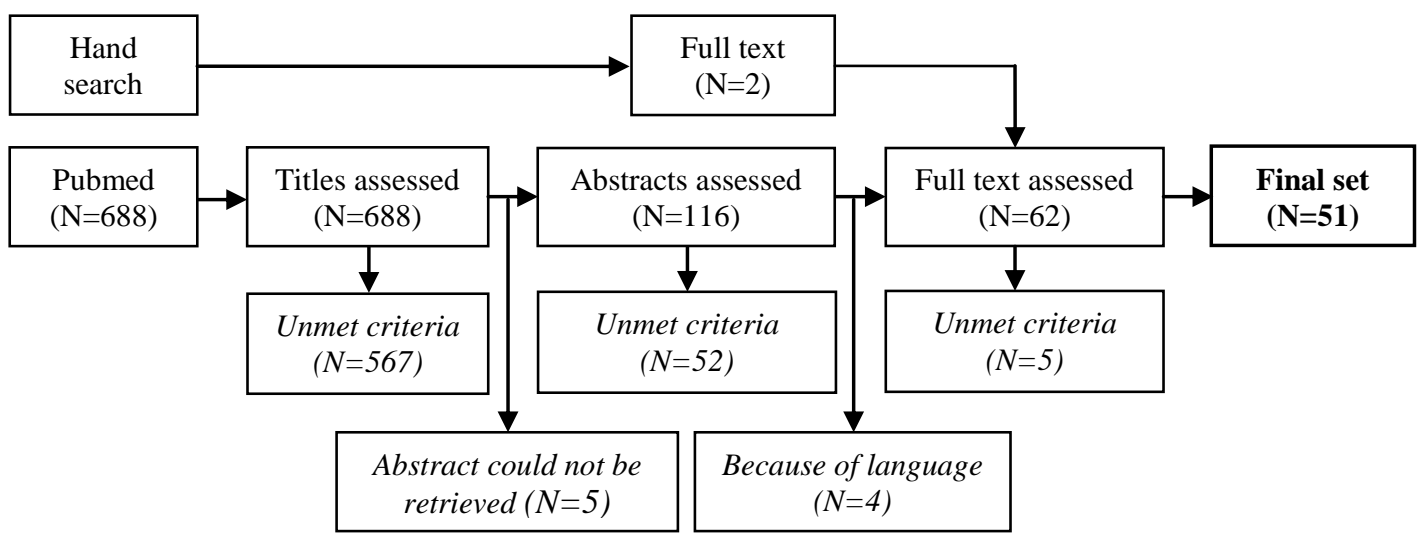

Figure 1. Overview in and exclusion titles, abstracts, and full text of the literature study process.

First, a systematic literature search of Pubmed was performed for records through September 2012 to identify articles of all studies which aimed to assess activity related risk factors for institutionalization of elderly persons. Pubmed was searched using the following search terms: risk factors, predictors, determinants, daily activities, activities of daily living, and instrumental activities of daily living combined in all possible ways with institutionalization. There were no limitations on dates of publication or venue. This resulted in an initial list of 688 titles. Secondly, the author and two other researchers independently screened and scored the initial set of titles (score 0 when not relevant, 1 point when maybe relevant and 2 points when expected to be highly relevant). Studies were selected as relevant if they reported risk factors for the institutionalization of elderly persons. Studies concerning rehabilitation, fall risks, cognitive decline or clinical conditions (e.g. stroke, dementia, Alzheimer) were excluded. Studies were selected for inclusion if they received a total score of minimal 2 points (the kappa for scoring titles between reviewer 1 and 2 was 0.56 , between reviewer 1 and 3 0.49 , and between reviewer 2 and 30.55 , which are all moderate). This second step in the data collection process resulted in a list of 116 abstract. Thirdly, the author and the same two researchers independently screened and scored all abstracts given the same in- and exclusion criteria for scoring the titles. Studies were selected for inclusion if they received a total score of 3 points or more (the kappa for scoring abstracts between reviewer 1 and 2 was 0.48 , between reviewer 1 and 30.44 , and between reviewer 2 and 30.62 , which are again all moderate). This resulted, after the exclusion of 4 non-English articles, in 60 full-text articles. In addition, a hand search was adopted to retrieve data. Efforts in these searches led to 2 additional studies on the problems of independently living elderly people with no cognitive decline. Finally, these 62 full-text studies were reviewed by the author, according to the aim of this literature study: creating an overview of articles that studied the 
possibility of daily activities being risk factors for the institutionalization of an elderly person. This led to the final number of 51 papers.

\subsection{Focus Groups}

Different focus group meetings were held in the Netherlands, United Kingdom, and France. For these focus group meetings the viewpoints of the individual participants as well as the group consensus were found to be important. Therefore the Metaplan method was used for the data collection ${ }^{8}$. This method ensured that all participants contributed to the outcome of the meeting, whilst the group discussion provided deeper understanding of the issues discussed. Three separate target groups were included: 1) elderly persons, 2) formal caregivers, and 3) informal caregivers. Separate focus groups were held for each of the three target groups, so that perspectives of the different groups could be captured.

\subsubsection{Participants}

Elderly persons and formal caregivers were contacted through care organizations. Informal caregivers were contacted through personal networks and through care organizations. Elderly persons were selected based on four criteria: 1) aged $60+, 2$ ) living at home, 3) no cognitive decline, and 4) receiving home care. The selection of formal caregivers was based on their work activities/profession. It was required that they worked closely with independently living elderly persons on at least a weekly basis. Informal caregivers had to meet one of the two criteria: 1) take care of an independently living elderly person on at least a weekly basis, or 2) to have taken care of an independently living elderly person on a weekly basis in the last year. During the recruitment the term robotics was mentioned, as well as the goal of the ACCOMPANY project. However it was clearly stated that the particular emphasis of this focus group would not be on the use of robots.

In total 113 persons participated in the study:

- Forty-one elderly persons (12 male, 29 female) with a mean age of 78.0 years (60 to 95 ) participated in focus group meetings in the Netherlands (11), United Kingdom (5) and France (25). All elderly persons were still living at home and receiving some form of care assistance (e.g. home care, tele-homecare system).

- Forty professional caregivers (2 male, 38 female) participated in focus group meetings in the Netherlands (14), United Kingdom (4) and France (22). Caregivers' professions varied from care workers, nurses, psychologists to managers. All professional caregivers worked closely with the elderly.

- Thirty-two informal caregivers (2 male and 30 female) participated in focus group meetings in the Netherlands (7), United Kingdom (5) and France (20). Informal caregivers took care of (one of) their parents, their spouse, neighbour, or their aunt. In two cases the elderly person taken care of was recently institutionalized and in one case the elderly person had recently passed away.

\subsubsection{Procedure}

The focus groups were carried out in separate groups of 4-10 participants in a room with a round table formation. Every participant received a marker pen and sticky notes. After the introduction and signing of the informed consent, participants were given one of the following questions (one for each group type):

- Elderly persons: Which problematic activities in (your) daily life are threatening (your) independent living?

- Formal caregivers: Which problematic activities in the daily lives of your clients are threatening their independent living?

- Informal caregivers: Which problematic activities in the daily lives of the person you care for are threatening his/her independent living?

The first assignment given to all participants was to individually write down as many activities they could think of on sticky notes answering the given question (one activity per sticky note). They were asked to stick their notes (randomly) on one surface when finished writing. Secondly, the participants were asked, as a group, to cluster all the gathered material per topic. During this clustering phase, discussion among participants was encouraged and more clarification was asked when needed. After clustering, all subgroups/topics were again discussed in the group. Finally participants were asked which group/topic they thought was the most important for independent living. Participants who had difficulty picking just one problem at the end of the focus group meeting, were given the following question: If we are going to create something to solve one of these problems, which problem should we solve first? The duration of the focus groups varied between 1.5 and 2 hours. 


\subsubsection{Data analysis}

Pictures were taken of the final clustered notes and all activities written on the notes were copied per group/topic. A short summary of every group/topic was compiled, as well as a general description of the whole session. A final list was composed for every focus group of those activities participants felt needed solving first.

\section{Results}

\subsection{Literature}

In the literature different variables related to nursing home admission could be identified. Nonetheless, only articles that studied the possibility of daily activities being risk factors were found to be interesting and will be discussed in this chapter. The systematic literature search led to 50 non-robotic-related studies and 1 robotrelated study on the problems of independently living elderly people. This robot-related study concerns the European Multi-Role Shadow Robotic System for Independent Living (SRS) project ${ }^{9}$, which produced a list of activities that make independent living challenging for elderly persons. This list was created without reference to robotics or technologies and therefore suitable for this literature search.

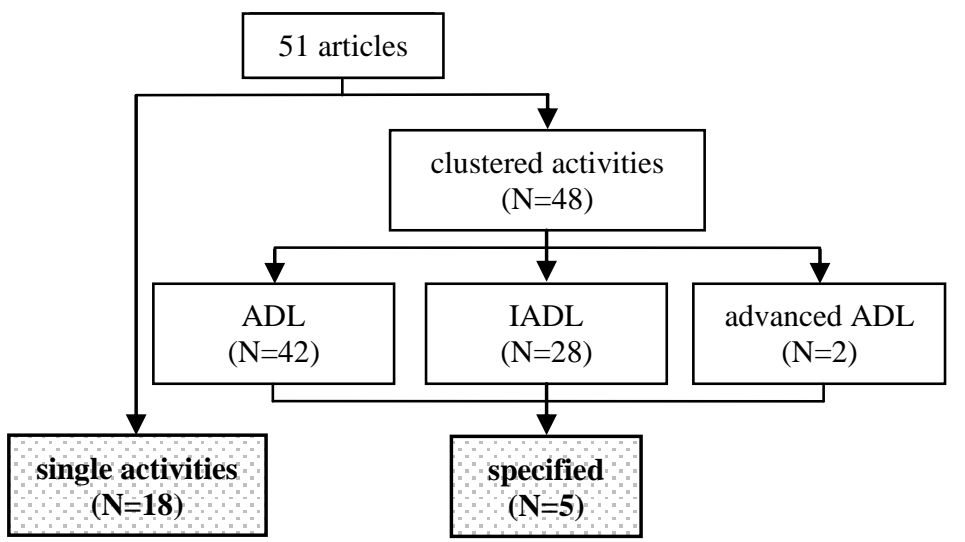

Figure 2. Classification of the final set of 51 articles. An article can appear in more than one group/sub-group.

Within the final set of 51 studies a distinction was made between articles studying clustered activities and articles studying single activities (see Figure 2). Articles could also be grouped in both sub-groups when one or more single activity was studied besides a clustered activity. Within the clustered activities group, three different clustered activities could be identified: activities of daily living (ADL), instrumental activities of daily living (IADL), and advanced activities of daily living (advanced ADL). ADL includes activities such as bathing, dressing, toileting, transfer, and eating. IADL includes the activities cooking, shopping, and cleaning. And finally, advanced ADL includes managing money and using the telephone. Out of the 48 articles studying the effect of one or more clustered activity on the institutionalization of elderly, 42 studies investigated ADL. From these 42 studies, 35 highlighted ADL as a risk factor (see Table 1). Out of the 28 studies that included IADL, 17 concluded that IADL was a risk factor for institutional. And out of the 2 studies investigating advanced ADL, 1 study found it to be a risk factor. Overall, ADL and IADL are seen as risk factors for the institutionalization of an elderly person. However, this does not provide sufficient insight in which activities specific are responsible for losing one's independence. Therefore we took it one step further and looked at the studies which specified the clustered activities. This resulted in 5 studies out of the clustered activities group ${ }^{10-14}$.

These 5 studies were added to the 18 studies from the single activities domain group (see figure 2) ${ }^{9,11,15-30}$. One article $^{11}$ was present in the single activities group as well as in the specified group; this therefore resulted in a total of 22 studies. Within these 22 articles a distinguish could be made between three different types of studies. The articles of the first type conducted risk factor analysis in order to investigate if activities could be seen as risk factors for the institutionalization of an elderly person. The second type includes one article that is focused on the characteristics of new entrants of nursing homes and the third type on the problematic activities mentioned by (still independent living) elderly persons without a risk factor analysis.

\begin{tabular}{c|c|c} 
& $\begin{array}{c}\text { Number of } \\
\text { articles }\end{array}$ & Risk factor \\
\hline ADL & 42 & 35 \\
\hline IADL & 28 & 17 \\
\hline $\begin{array}{c}\text { advanced } \\
\text { ADL }\end{array}$ & 2 & 1
\end{tabular}

Table 1. Overview of the number of article in which ADL/IADL/advanced $\mathrm{ADL}$ is mentioned as a risk factor for institutionalization. 


\subsubsection{Type 1 -Risk factor analysis of activities}

Nineteen studies ${ }^{1-29}$ investigated if one or more single activities were risk factors for the institutionalization of an elderly person through a risk factor analysis. An overview of these studies can be found in Table 2. From this table it can be said that mobility - d4, changing body position (e.g. sitting and getting up) - d410, walking $\mathrm{d} 450$, washing oneself $-\mathrm{d} 510$, toileting $-\mathrm{d} 530$, dressing $-\mathrm{d} 540$, feeding $-\mathrm{d} 550 / \mathrm{d} 560$, taking medication $\mathrm{d} 570$, preparing meals $-\mathrm{d} 630$, and interpersonal interaction \& relationship $-\mathrm{d} 7$ were considered to be a risk factor by at least one study.

Table 2. Overview of activities addressed in the literature. Shading indicates activities indentified as risk factor.

\begin{tabular}{|c|c|c|c|c|c|c|c|c|c|c|c|c|c|c|c|c|c|c|c|c|}
\hline & ICF & 党 & 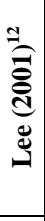 & 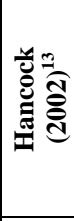 & 总告 & 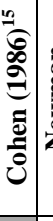 & 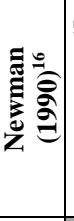 & 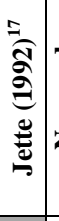 & 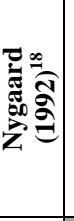 & 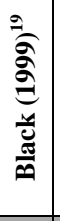 & 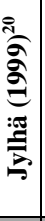 & . & . & 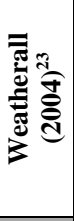 & | & 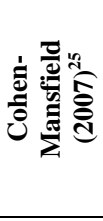 & 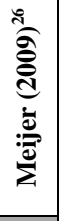 & |ct & 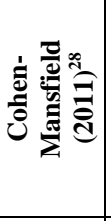 & 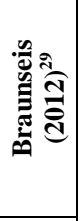 \\
\hline Mobility & $\mathrm{d} 4$ & & & & & $\mathrm{x}$ & & $\mathrm{x}$ & & $\mathrm{x}$ & $\mathrm{x}$ & $\mathrm{x}$ & & $\mathrm{x}$ & & & $\mathrm{x}$ & & & \\
\hline $\begin{array}{l}\text { Changing body } \\
\text { position }\end{array}$ & $\mathrm{d} 410$ & $\mathrm{x}$ & $\mathrm{x}$ & $\mathrm{x}$ & $\mathrm{x}$ & & & & & & & & & & & & & & & \\
\hline Walking & $\mathrm{d} 450$ & & & & & & & & & & & & & & & & & & & $\mathrm{x}$ \\
\hline Climbing stairs & $\mathrm{d} 4551$ & & & & & & & & & & & & $\mathrm{x}$ & & 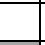 & & & & & \\
\hline $\begin{array}{l}\text { Washing } \\
\text { oneself }\end{array}$ & d510 & $\mathrm{x}$ & $\mathrm{x}$ & & $\mathrm{x}$ & & & & & & & & & & $\mathrm{x}$ & & & & & \\
\hline Toileting & d530 & $\mathrm{x}$ & $\mathrm{x}$ & $\mathrm{x}$ & $\mathrm{x}$ & & $\mathrm{x}$ & & & & & & & & & & & & & \\
\hline Dressing & d540 & $\mathrm{x}$ & - & $\mathrm{x}$ & & & & & $\mathrm{x}$ & & & & & & & & & & & \\
\hline Feeding & $\begin{array}{l}\text { d550 } \\
\text { d560 }\end{array}$ & $\mathrm{x}$ & $\mathrm{x}$ & $\mathrm{x}$ & $\mathrm{x}$ & & $\mathrm{x}$ & & $\mathrm{x}$ & & & & & & & & & & & \\
\hline $\begin{array}{l}\text { Taking } \\
\text { medication }\end{array}$ & d570 & $\mathrm{x}$ & & & & & & & & & & & & & & & & & & \\
\hline Shopping & d620 & & & & & & & & & & $\mathrm{x}$ & & & & & & & & & \\
\hline $\begin{array}{l}\text { Preparing } \\
\text { meals }\end{array}$ & d630 & $\mathrm{x}$ & & & & & & & & & & & & & & & & & & \\
\hline $\begin{array}{l}\text { Interpersonal } \\
\text { interactions } \\
\text { and } \\
\text { relationships }\end{array}$ & d7 & & & & & & & & & & & & & & & $\mathrm{x}$ & & $\mathrm{x}$ & $\mathrm{x}$ & \\
\hline
\end{tabular}

\subsubsection{Type 2 - Characteristics of new entrants nursing home}

From the 22 studies, one study ${ }^{10}$ looked at the characteristics of a sample $(\mathrm{N}=125)$ of new entrants in four nursing homes. The majority of these new entrants were, concerning ADL, the most dependent in washing $\mathrm{d} 510(50.4 \%)$, followed by dressing $-\mathrm{d} 540(48.8 \%)$, toileting $-\mathrm{d} 530(28.8 \%)$, mobility $-\mathrm{d} 4(26.4 \%)$, and eating - d550 (10.4\%). Concerning IADL, new entrants were most dependent in cleaning - d6401/d6402 $(87.2 \%)$, followed by cooking - d630 (81.6\%), laundry/ironing - d6400 (75.4\%), outside mobility - d4602 $(66.4 \%)$, and administration $-\mathrm{d} 860(68.0 \%)$. None of these specified activities were individually included in a risk factor analysis.

\subsubsection{Type 3 - List of challenging activities}

The European Multi-Role Shadow Robotic System for Independent Living (SRS) project ${ }^{9}$, together with the Dutch study into The most recurrent problems of the independently living elderly: recommended assistive devices and solutions ${ }^{30}$ form the third group type. Both produced a list of activities that make independent living challenging for elderly persons. The SRS study used qualitative and quantitative methodologies. First they included in focus group sessions a direct question about difficulties of daily living and some complementary questions about degree of difficulty and its causes. Elderly persons as well as family cares, professional caregivers, and health professionals participated in both the focus group session as the questionnaire. The Dutch study $^{30}$ only conducted a qualitative study which resulted in a list of the 10 most mentioned problems of independent living elderly. The prioritized difficulties with daily tasks mentioned in the studies were reading d166, mobility-related ones (walking inside/outside - d450/d4602, climbing up stairs - d4551, reaching for objects - d4452, sitting \& getting up - d410, carrying heavy objects - d430, and bending - d4105), self-care related (washing oneself $-\mathrm{d} 510$, caring for body parts $-\mathrm{d} 520$, toileting $-\mathrm{d} 530$, dressing $-\mathrm{d} 540$, feeding - 
d550/d560, taking medication - d570), domestic life (shopping - d620, preparing meals - d630, doing housework - d640), and loneliness - d7.

\subsection{Focus groups}

From the focus group meetings a total of 43 different problems were gathered (see figure 3). Not all 43 problems were mentioned in every focus group. The majority of the collected problematic activities raised during the focus group meetings could be grouped into section d, Activities and Participation, of the ICF. The other types of problems mentioned were not specifically activities of individuals but more of the environment (e.g. being looked after). For the second step of the session, participants of each focus group were asked to cluster the problems per topic. Although not all 43 problems were mentioned in every group, the topics created after clustering showed great overlap. For example: The Dutch elderly people, the formal caregivers, as well as the informal caregivers all mentioned one topic in their focus group Self-care. However, this topic contained different problems for every focus group (see Table 3). This was similar for the other overlapping clustered topics. To complete the problem assessment session in the focus group meetings, participants were asked to rank the problems. Problems that were often mentioned during the group session were not ranked as most problematic

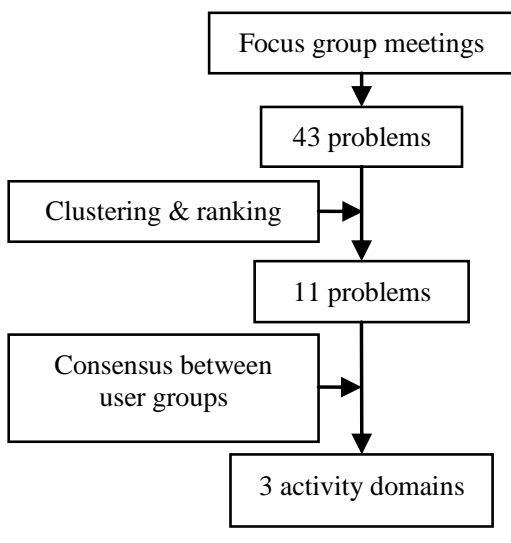

Figure 3. Steps in the analysis of focus group results. per se, as current solutions sometimes were found to be sufficient. One such example is the problem of preparing meals, which was mentioned multiple times in most focus group meetings. Current solutions (e.g. meal delivery services, microwave meals) meant that this problem was no longer perceived as a severe threat for the independence of elderly persons.

Table 3. Decomposition of the Self-care cluster for 3 Dutch focus groups..

\begin{tabular}{l|l|l} 
Elderly & Formal caregivers & Informal caregivers \\
\hline $\begin{array}{l}\text { Getting (un)dressed } \\
\text { Putting shoes on/off } \\
\text { Showering }\end{array}$ & $\begin{array}{l}\text { ADL care } \\
\text { Combing hair } \\
\text { Getting (un)dressed (2x) } \\
\text { Washing hair }\end{array}$ & $\begin{array}{l}\text { Getting (un)dressed }(2 \mathrm{x}) \\
\text { Personal care } \\
\text { Toileting } \\
\text { Showering }\end{array}$ \\
& $\begin{array}{l}\text { Putting cream on legs } \\
\text { Washing back } \\
\text { Toileting (3x) } \\
\text { Putting stockings on/off }(3 \mathrm{x})\end{array}$ & \\
Putting shoes on/of & \\
Showering & \\
Cutting nails (2x) & \\
Eating & \\
Making sandwiches &
\end{tabular}

The clustering and ranking of the problems resulted in eleven main problems, which are shown in Table 4. All clustered activities contain a number of problems that differed per focus group session (similar to the example of Self-care in Table 3). In table 4 also an overview is given to the combined priorities over the three countries, specified per type of user. Most of these problems were multi-dimension and became a threat for several reasons; e.g. opening the front door presents a mobility issue, but also poses the problem that it is difficult for the elderly to know if it is safe to open the door. Table 4 also visualizes the consensus between the three different groups. Following this consensus a priority list could be created. The three activities described below received the highest priority, as they were seen as most threatening for the independence of elderly by participants from all the three target groups. Additionally, the problematic activities for these three overall activities written by the participants on the sticky notes are added, categorized by ICF number:

1) Self-care activities: When an elderly person is not able to take care of their personal hygiene, then he or she becomes dependent, especially when getting up in the morning or going to bed in the evening. Consequently, people have to adapt their daily schedule to the schedule of their caregiver. Self-care problems mentioned by the focus group participants were: Washing oneself $-\mathrm{d} 510$, caring for body parts $-\mathrm{d} 520$, toileting $-\mathrm{d} 530$, dressing $-\mathrm{d} 540$, eating $-\mathrm{d} 550$, drinking $-\mathrm{d} 560$, and taking medication $-\mathrm{d} 570$. 
2) Mobility: Living independently at home becomes extremely difficult as one is not mobile any more. Mobility problems mentioned in the focus group session were: Walking inside - d450, climbing stairs - d4551, sitting \& getting up - d410, lifting and carrying objects - d430, and bending - d4105. Mobility problems can also make other activities problematic (e.g. opening the front door or shopping).

3) Social isolation: Social isolation is caused by the decrease or even lack of activities concerning interpersonal interaction and relationships. Problems mentioned by elderly people, formal caregivers, and informal caregivers in the focus group session were: Loneliness, lack of family/friends, going outside, keeping in touch with family/friends, safety (being alone at night), isolation, and lack of hobbies.

Table 4. Overview of the prioritised (shaded) clustered problems expressed in the focus group meetings in the Netherlands, the UK, and France.

\begin{tabular}{l|l|l|l}
\hline Communication support for the hearing impaired & & & \\
\hline Costs (e.g. poverty) & & & \\
\hline Housing adaptations & & & \\
\hline Social isolation & & & \\
\hline Lack of hobbies & & & \\
\hline Mobility & & & \\
\hline Monitoring & & & \\
\hline Opening the front door & & & \\
\hline Self-care activities & & & \\
\hline Shopping & & &
\end{tabular}

The next step was to combine the results derived from the literature with the results of the focus group meetings. Therefore the results from the 22 studies and the focus group meetings were combined in one table (see Table 5). The activities mentioned in the second column of the table are not all on the same level; e.g. mobility - d4 (no. 2) includes the 7 sub-activities listed below (no. 3 - no. 9). This is similar for the activity doing household d640 (no. 19): this activity also includes the 3 sub-activities listed below (no. 20 and no. 21). The numbers in the column of type 1 represent the number of studies concluded the activity to be a risk factor and the total number of studies investigated the activity; e.g. changing basic body position - d410 (no. 3) was found to be a significant risk factor by 3 out of the 4 studies investigating this activity. The numbers in the column of type 2 represent the percentage of new entrants in nursing homes having difficulties with the specific activity.

When looking at the overlap between the literature and the focus group meeting results, it can be seen that there is an overlap for the activities within the domains mobility - d4 (no. 2 - no. 9), self-care - d5 (no. $10-$ no. 16), and interpersonal interaction and relationships $-\mathrm{d} 7$ (no. 23). The relevance of problematic domestic activities d6 (no. 17 - no. 22) found in the literature was not confirmed by the results of the focus group meetings. However, these domestic activity problems were mentioned in the focus group sessions, but were not highlighted as most problematic.

Table 5. Overview of activities indentified in the focus groups and in the three different types of literature (i.e. type 1: Risk factor analysis of activities, type 2: Characteristics of new entrants nursing home, and type 3: List of challenging activities) threatening the independent living of elderly persons in order of ICF number.

\begin{tabular}{c|c|l|l|l|l|l} 
& & \multirow{2}{*}{ Focus } & \multicolumn{3}{|c}{ Literature } \\
\cline { 6 - 7 } No. & Activity & ICF & groups & Type 1 & Type 2 & Type 3 \\
\hline $\mathbf{1}$ & Reading & $\mathrm{d} 166$ & & & & \\
\hline $\mathbf{2}$ & Mobility & $\mathrm{d} 4$ & & $7 / 7$ & $26.4 \%$ & \\
\hline $\mathbf{3}$ & Changing basic body position & $\mathrm{d} 410$ & & $3 / 4$ & & \\
\hline $\mathbf{4}$ & Bending & $\mathrm{d} 4105$ & & & & \\
\hline $\mathbf{5}$ & Lifting and carrying objects & $\mathrm{d} 430$ & & & & \\
\hline $\mathbf{6}$ & Reaching & $\mathrm{d} 4452$ & & & & \\
\hline
\end{tabular}




\begin{tabular}{|c|c|c|c|c|}
\hline 7 & Walking & $\mathrm{d} 450$ & & \\
\hline 8 & Climbing stairs & $\mathrm{d} 4551$ & & \\
\hline 9 & Outside mobility & $\mathrm{d} 4602$ & & $66.4 \%$ \\
\hline 10 & Washing oneself & $\mathrm{d} 510$ & $3 / 4$ & $50.4 \%$ \\
\hline 11 & Caring for body parts & d520 & & \\
\hline 12 & Toileting & $\mathrm{d} 530$ & $3 / 5$ & $28.8 \%$ \\
\hline 13 & Dressing & $\mathrm{d} 540$ & $2 / 3$ & $48.8 \%$ \\
\hline 14 & Eating & $\mathrm{d} 550$ & \multirow{2}{*}{$3 / 6$} & $10.4 \%$ \\
\hline 15 & Drinking & $\mathrm{d} 560$ & & \\
\hline 16 & Taking medication & $\mathrm{d} 570$ & $1 / 1$ & \\
\hline 17 & Shopping & d620 & & \\
\hline 18 & Preparing meals & d630 & $1 / 1$ & $81.6 \%$ \\
\hline 19 & Doing household & $\mathrm{d} 640$ & & \\
\hline 20 & Washing and drying clothes and garments & d6400 & & $75.4 \%$ \\
\hline \multirow{2}{*}{21} & Cleaning cooking area and utensils & d6401 & & \multirow{2}{*}{$87.2 \%$} \\
\hline & Cleaning living area & d6402 & & \\
\hline 22 & Interpersonal interaction and relationships & $\mathrm{d} 7$ & $3 / 3$ & \\
\hline 23 & Basic economic transactions & $\mathrm{d} 860$ & & $68.0 \%$ \\
\hline
\end{tabular}

\section{Discussion}

The goal of this study was to find an answer to the following question: Which problematic activities in daily life most threaten the independence of elderly persons? This study showed that activities concerning the ICF domains mobility $-\mathrm{d} 4$, self-care activities $-\mathrm{d} 5$, and social isolation $-\mathrm{d} 7$ were regarded both in literature and by the participants of the focus group sessions as the most problematic and threatening for the independence of elderly persons. However, it has also become clear there is no single activity that can be selected as the main activity causing a loss of independence. Some participants of the focus groups had difficulty picking just one problem at the end of the focus group meeting, resulting in an underlining of the multidimensional nature of the problems. It is often a combination of problematic activities which is person-specific. This is understandable in light of the diversity in age related loss of abilities between individuals and the diversity in living environments between individuals.

In principle, the elderly age in much the same way everywhere, as they face similar problems resulting from physical and mental decline. The perspective of the three countries was introduced as there are differences in the way care is provided and the range of activities supported by public care provision. The assumption was that this would significantly differ between countries and was expected to influence the problems experienced and/or reported by the participants. The difference in the results between the countries did not reflect this. There were some small differences: in France the problem concerning the coordination of care was quite prominent, while this was not mentioned in the Netherlands or the United Kingdom. But regarding the problematic activities, the overlap between the three countries was obvious.

The correspondence between the countries was notable high, however in the United Kingdom the focus was somewhat more on disabilities (e.g. physical and psychological limitations) rather than activities. This may be influenced by the fact that the focus groups in the three countries were all moderated by different facilitators, resulting in some variations in the adopted method. This introduced some difficulty in performing the final step in prioritizing the activities between the countries. Nonetheless, the results between the three countries were in line and therefore one list of problems could be created. The group sizes also varied considerably between the three countries. However, this was of no concern in analyzing the data as the results between the countries showed great overlap to integrate the list of problems. The inclusion criteria selections were not particularly specific (e.g. elderly persons only had to meet three criteria and informal caregivers only one) and there were no inclusion criteria concerning the gender balance of the sample. This resulted in an unbalanced sample size between genders, as $86 \%$ of all the participants were female. When looking at the balance between male female for all three user groups it can be found that $71 \%$ of the elderly people, $95 \%$ of the professional caregivers, and $94 \%$ of the informal caregivers were female. Overall, females have a higher life expectancy, however the percentage of female elderly persons in the focus group session is still higher compared to the European average in 2011. According to Eurostat ${ }^{31} 62 \%$ of the European population aged $75+$ was female. The 
overrepresentation of females among the professional caregivers and informal carers may be explained by the fact that care professions/tasks these days are still mainly executed by females. Further, people with cognitive difficulties, who form a large and growing group, were excluded. For this group a different set of activities will prove to be a threat to independent living. Although the inclusion criteria resulted in an overrepresentation of females, we included a broad group of participants and we think these participants can be seen as representative for the general population.

The aim of this paper was to identify meaningful tasks for robot support of elderly persons. For this we analyzed critical activities supporting independent living. The results do not imply that all these task should be performed by robotic systems. When tasks can be solved as effectively by parsimonious or cheaper technology, robots should be discarded. The added value of a robotic system developed should be made clear over alternative (simpler) technology or human care solution. This will be essential to use in practice sooner or later.

In general a robot is an embodied system that is able to perform automated tasks, involving physical movement and/or force exertion. Looking at the three problematic activity domains (i.e. self-care activities, mobility, and social isolation), it is clear that robots could obviously support a number of these tasks, but for other tasks it is more questionable. For example: several activities within the domain self-care (e.g. washing, toileting, dressing, and eating) and the domain mobility (e.g. climbing stairs, lifting and carrying objects) involve physical movement and/or force exertion. These activities could therefore be interesting for a robotic system. The third problematic domain, social isolation, may be less suitable to be solved by a robotic system as there is most likely no need for physical movement and/or force exertion. There are already several (low cost) non-robotic ICT technologies available to support social interaction (e.g. Skype, tele-homecare systems) and it is easier to place a tablet in every room than to create an expensive tablet on wheels that can navigate through the house without problems. Nevertheless, there are exceptions such as the social robot Paro ${ }^{32}$, which also addresses social isolation and is a great success.

Further research should address the issues mentioned above and take the next step towards the development of a successful service robot and investigate which of the activities are best continued with. In making this selection the technical feasibility and the expected market potential will be decisive. Therefore, also the current care support available for elderly persons per country should be taken into account in assessing the potential of the outcomes of the ACCOMPANY project. Developing a solution in the ACCOMPANY project for a subset of this list of activities will result in a wish list for the remaining activities.

\section{Conclusion}

To conclude, this study explored the problematic activities threatening independent living of elderly persons through literature and focus group meetings. What became apparent is that a clear set of activities could be identified. Nonetheless it was impossible of finding one single activity that, once becoming problematic, leads to a decision of having to leave home. It is most often a combination of problems that leads to such a decision, based on the abilities of the person (patient) in relation to their own perception, their wishes and the environment of independent living (in a social, physical and financial sense). From the literature and the focus group meetings we found the most important activities threatening the independence of elderly persons concern the activity domains mobility $-\mathrm{d} 4$, self-care activities $-\mathrm{d} 5$, and social isolation $-\mathrm{d}$ 7. However, the combination of problems can differ between individuals. A future service robot could therefore be designed to support a diverse need of activities. Further, the needs of future users is only one variable to consider in the development of a robot for elderly people. In order to create a successful robot, the influence of the current care support available for elderly persons (e.g. home care support, the supply of institutional services) must be considered, too. Further, it should also be noted that not all the problems mentioned in this article are necessarily best-solved by robotics.

The Care-O-bot巴 ${ }^{\circledR}$ robot's functionality will only address a subset of the activities identified in this study and selected the basic fetch and carry task as functionality (related to the domains mobility - d4 and self-care $-\mathrm{d} 5$ ). During this project robot behaviour, both functional and social, will be developed to effectively deliver this functionality. The set of prioritized activities for which people need support is hoped to function as both as an inspiration and as a wish list for future robot development.

\section{Acknowledgments}

The authors are grateful to colleagues in the ACCOMPANY consortium (The University of Hertfordshire, United Kingdom; Hogeschool Zuyd, The Netherlands; Fraunhofer, Germany; University of Amsterdam, The Netherlands; University of Sienna, Italy; Maintien en Autonomie à Domicile des Personnes Agées, France; and 
University of Birmingham, United Kingdom; University of Twente, the Netherlands; University of Warwick, United Kingdom). We are also grateful to the focus group participants that agreed to take part in our study (written consent was obtained from all participants) and provide the contrasting views used in this text. Possible inaccuracies of information are under the responsibility of the project team. The text reflects solely the views of its authors. The European Commission is not liable for any use that may be made of the information contained therein.

\section{Declaration of Interest statement}

The work described in this project was partially funded by the European project ACCOMPANY (Acceptable robotiCs COMPanions for AgeiNg Years). Grant agreement no: 287624.

\section{References}

[1] Miller EA, Weissert WG. Predicting elderly people's risk for nursing home placement, hospitalization, functional impairment, and mortality: A Synthesis. Med Care Res Rev 2000;53(3):257-65.

[2] Cameron C, Moss P. Care work in Europe: Current understandings and future directions. Oxford: Routledge; 2007. $176 \mathrm{p}$.

[3] Vlaskamp F, Soede M, Gelderblom GJ. History of assistive technology: 5000 years of technology development for human needs. Heerlen, the Netherlands: Zuyd University of Applied Sciences; 2011. 98p.

[4] Bekey G, Ambrose R, Kumar V, Sanderson A, Wilcox B, Zheng Y. WTEC panel report on international assessment of research and development in robotics (Final report). World Technology Evaluation Center; 2006. 289 p.

[5] Butter M, Rensma A, van Boxsel J, Kalisingh S, Schoone M, Leis M, Gelderblom GJ, Cremers G, de Wilt M, Kortekaas W, Thielmann A, Cuhls K, Sachinopoulou A, Korhoven I. 2008. Robotics for healthcare (Final report). http://www.tno.nl/downloads/TNOKvL report RoboticsforHealthcare.pdf. Accessed 2012 Dec 12 [6] Acceptable robotiCs COMPanions for AgeiNg Years (ACCOMPANY) [Internet]. Available from: http://accompanyproject.eu/. Accessed 2012 Dec 12

[7] World Health Organization. Towards a common language for functioning, disability and health: The international classification of functioning, disability and health. Geneva: World Health Organization; 2002. 23 p. http://srs-project.eu/srs deliverables. Accessed 2012 Dec 12

[8] Schnelle E. The Metaplan-Method: Communication Tools for Planning and Learning Groups. Quickborn, Hamburg; 1979. 63 p.

[9] Facal D, Pigini L, Mast M, Blasi L., Cavallaro FI. Deliverable D1.2 - a: Detailed user requirements environment definition, general guidelines on ethical concerns and SRS scenario report. European Commission; 2011. 133 p.

[10] van Rensbergen G, Pacolet J. Instrumental activities of daily living (I-ADL) trigger an urgent request for nursing home admission. Arch Public Health 2012;70(2).

[11] Greenberg JN, Ginn A. A multivariate analysis of the predictors of long-term care placement. Home Health Care Serv Q 1979;1:1:75-99.

[12] Lee T, Kovner CT, Mezey MD, Ko IS. Factors influencing long-term home care utilization by the older population: implications for targeting. Public Health Nurs 2001;18:6:443-9.

[13] Hancock R, Arthur A, Jagger C, Matthews R. The effect of older people's economic resources on care home entry under the United Kingdom's long-term care financing system. J Gerontol B Psychol Sci Soc Sci 2003;58:1;S11-20.

[14] Matsumoto M, Inoue K. Predictors of institutionalization in elderly people living at home: the impact of incontinence and commode use in rural Japan. J Cross Cult Gerontol 2007;54:4:244-51.

[15] Cohen MA, Tell EJ, Wallack SS. Client-related risk factors of nursing home entry among elderly adults. J Gerontol 1986;41:6;758-92.

[16] Newman SJ, Struyk R, Wright P, Rice M. Overwhelming odds: caregiving and the risk of institutionalization. J Community Health 1990;15:2;123-35.

[17] Jette AM, Branch LG, Sleeper LA, Feldman H, Sullivan LM. High-risk profiles for nursing home admission. J Gerontol 1992;32:5;634-40.

[18] Nygaard HA, Albrektsen G. Risk factors for admission to a nursing home: A study of elderly people receiving home nursing. Scand J Prim Health Care 1992;0:2;128-33.

[19] Black BS, Rabins PV, German PS. Predictors of nursing home placement among elderly public housing residents. Gerontologist 1999;39:5;559-68.

[20] Jylhä M, Hervonen A. Functional status and need of help among people aged 90 or over: a mailed survey with a total home-dwelling population. Scand J Public Health 1999;27:2;106-11. 
[21] Hays JC, Pieper CF, Purser JL. Competing risk of household expansion or institutionalization in late life. J Gerontol B Psychol Sci Soc Sci 2003;58:1:S11-20.

[22] Schur D, Whitlatch CJ. Circumstances leading to placement: a difficult caregiving decision. Lippincotts Case Manag 2003;8:5;187-95;quiz 196-7.

[23] Weatherall M, Slow T, Wiltshire K. Risk factors for entry into residential care after a support-needs assessment. N Z Med J 2004;117(1202). http://journal.nzma.org.nz/journal/117-1202/1075/. Accessed 2013 Jan 4

[24] Gill TM, Allore HG, Han L. Bathing disability and the risk of long-term admission to a nursing home. J Gerontol A Biol Sci Med Sci 2006;61:8;821-5.

[25] Cohen-Mansfield J, Wirtz PW. Characteristics of adult day care participants who enter a nursing home. Psychol Aging 2007;22:2;354-60.

[26] de Meijer CAM, Koopmanschap MA, Koolman XHE, van Doorslaer EKA. The role of disability in explaining long-term care utilization. Med Care 2009;47:11;1156-63.

[27] Kendig H, Browning C, Pedlow R, Wells Y, Thomas S. Health, social and lifestyle factors in entry to residential aged care: an Australian longitudinal analysis. Age Ageing 2010;39:3;342-9.

[28] Cohen-Mansfield J, Wirtz PW. Predictors of entry to the nursing home: does length of follow-up matter? Arch Gerontol Geriatr 2011;53:3;309-15.

[29] Braunseis G, Deutsch T, Frese T, Sandholzer H. The risk for nursing home admission (NHA) did not change in ten years - a prospective cohort study with five-year follow-up. Arch Gerontol Geriatr 2012;54:2;e637.

[30] Crützen C, Dhome C, Smits Y, Spierts N. Meest voorkomende problemen bij zelfstandig wonende ouderen en aanbevolen hulpmiddelen en oplossingen. [The most recurrent problems of the independently living elderly: recommended assistive devices and solutions]. Heerlen, the Netherlands: Zuyd University of Applied Sciences; 2010.

[31] Eurostat [internet]. Population on 1 January by broad age group and sex. [cited 2013 Jan 11]. Available from http://epp.eurostat.ec.europa.eu/portal/page/portal/eurostat/home

[32] Paro robot [internet]. Available from http://www.parorobots.com/ 